\author{
Advanced Studies in Medical Sciences, Vol. 1, 2013, no. 1, 1 - 10 \\ HIKARI Ltd, www.m-hikari.com
}

\title{
Near-Death Experiences in Central Asia
}

\author{
Birk Engmann $^{1}$ and Muyassar Turaeva ${ }^{2}$ \\ ${ }^{1}$ Brandis Rehabilitation Centre, Department of Neurology, Germany \\ ${ }^{2}$ Bielefeld University, Department of Public Health, Germany
}

Correspondence to: Dr. med. Birk Engmann

Brandis Rehabilitation Centre

Department of Neurology

Am Wald, 04821 Brandis, Germany

e-mail: oa.engmann@fachklinikum-brandis.de

Copyright (C 2013 Birk Engmann and Muyassar Turaeva. This is an open access article distributed under the Creative Commons Attribution License, which permits unrestricted use, distribution, and reproduction in any medium, provided the original work is properly cited.

\begin{abstract}
The article deals with pilot data of a study of Uzbek people, mainly clinical- death survivors, in regard to possible near-death experiences (NDE). Evaluation of the first 13 cases showed that there is no regular sequel of experiences in NDE. In the thirteen cases there were no reports of tunnel phenomena or of film-clip-like experiences. Instead, acoustic phenomena, visions of light, feelings, and out-ofbody experiences were most common. NDE are not stringently connected with clinical death, but also happened under a "normal" operation. Nor do they always appear in cases of clinical death and resuscitation. Also, NDE are influenced by one's memories and cultural background.

In conclusion, pilot data support the criticism that the term NDE is too broad, and demonstrate neuropsychological phenomena of multiple realizations of the same mental functions.
\end{abstract}

Keywords: near-death experiences, NDE, Muslim population, Uzbekistan, Central Asia

\section{Introduction}

Near death experiences are a widely discussed phenomenon. Most investigations derive from countries of the Western world where reports of near-death experiences 
(NDE) are very common in the press, TV, and books. Moreover, discussion about NDE has a long tradition in European society. In the $19^{\text {th }}$ century, the same disputes as current ones occurred concerning the origin and spiritual importance of NDE [1]. A problem in studying NDE is the influence of secondary reprocessing of phenomena under a person's cultural and religious views. Additionally, it is worth discussing whether such expectations influence frequency and pattern of NDE, as had previously been shown in a study of the influence of atheism in East- Germany (former GDR) as compared to the more religious western part of Germany. NDE and religious interpretations of it were more frequent in the West [6]. Such influences are a distortion factor in the search for possible core phenomena directly linked to clinical death. Because of these problems the authors started a study of NDE in Uzbekistan. This article provides pilot data. We chose a central Asian country because of its unique circumstances in regard to NDE. It is a country with Muslim religion but also was under atheist influence for about 80 years as a part of Soviet Union. Furthermore, many local traditions still play an important role in religion. We had expected a population that was poorly informed about NDE and therefore would provide less "prejudiced" reports, in contrast to reports from "Western" people who mostly had already thought about the problem of NDE before their personal experience of it, or perhaps received "orientation" after their experience from the internet or press. Furthermore, data from the Islamic world on NDE are rare, and may offer interesting contrasts to Christian views of it.

\section{Method}

Patients were recruited by targeted sampling and, additionally, snowball sampling. Targeted sampling was conducted by inspection of files of the last 20 years of the Scientific Centre of Emergency Medicine in Urgench. Search criterion was reanimation. Furthermore, we included cases hospital physicians remembered having had near-death experiences. Patients were interviewed in 2011 in the Uzbek city of Tashkent and in the Khwarezm region. All patients had undergone a previous hospital stay in the hospital of Urgench. In-depth interviews with openended questions were used. Such questions require more than a mere yes or no response and avoid tendentious answers according to intention of the question. Suggestive questions were avoided, and that's why questionnaires about NDE were not used. The patient is enabled to talk freely. Only at the end of the interview were patients asked whether they had already heard something about NDE. We used these methods because criteria of NDE are not specific and, moreover, can also occur as a part of other human experiences.

\section{Case histories}

Case 1

Uzbek, male, Muslim, age at interview: 23 years old (to be abbreviated as “y. o."). 
At the age of 7 years the patient suffered from severe infection. Heavy side effects occurred after a concomitant vaccination. Coma followed and two reanimations. About that time the patient has amnesia. He does not remember any sensations which could be connected with that event.

Patient was well informed about NDE via TV.

Case 2

Uzbek, male, Muslim, age at interview: 39 y. o.

Three months before our interview he had a car accident, and had been squeezed inside a demolished car, and lost consciousness. After waking up he saw doctors around him. He remembers that he wanted to go to the toilet and talked to the physicians. Afterwards he underwent an operation of the abdomen, and was given an artificial anus. Two days after the operation he fell into a coma for 3 days and during it he was reanimated with electroshock therapy. When he got consciousness back, he remembers that he heard voices like "on a bazaar when everything swooshs." He also saw his grandfather in blue traditional clothes (chalat), who said something to him which the patient did not understand, but he reports that "others asked me why I lay down." The patient, however, did not remember either when the vision occurred or who these "others" were. Finally the patient said: "I know about such things that people see that the soul comes out when the heart stops but I didn't see such stuff."

Case 3

Uzbek, female, Muslim, age at interview: 44 y. o.

Two years ago, the patient had a hip operation and was reanimated with electroshock therapy. She remembers that before narcosis she had been laid on the operation table and got an injection. Then it was like a dream. She saw lights as in the operating room, felt that she was up and saw the doctors doing something. Afterwards a feeling of moving around a thing like a table occurred. Noise occurred like tick-tick-tick, followed by a zigzag- pattern she described and painted as a row of tents looking like this: $\Lambda \Lambda \Lambda \Lambda \Lambda \Lambda$

The patient admits that she had been well informed long before the operation about people who see something under narcosis. Even her relatives asked her about what she saw immediately after operation.

Case 4

Uzbek, female, Muslim, age of interview: 35 y. o.

Four years ago the patient gave birth to twins. Something broke (rupture of uterus?), and she had abdominal pain. Later she was reanimated. Afterwards she remembered that she heard a voice in her native language saying: "Sit down, it is smooth and soft." It was not a certain person, just somebody, "a voice". Furthermore, her mind was clear, and she asked herself why she had been transferred to another ward. Then she touched a garment, something white and smooth with something in it which was "indescribable". 
She sat in a smooth stuff, but also flew to somewhere in a white- blue space. At the end she flew to a door - impossible to describe but with ornaments all over it; not like in Khiva (a historical city in Uzbekistan famous for its architecture, a. a.). "You haven't seen this before!", she expressed. What was the colour of the door? "Light!" and then: "yellow". "It must be paradise." Furthermore, she sprinted to open the door to see what's inside, and thought how this might be constructed to hold together. She was in a hurry. Voices told her the door won't be open and don't enter. When she got back to life her first words to the physicians were allegedly: "Why did you return me, I was in paradise!" (This is only her remembrance. The physicians did not tell her this. a. a.) In the interview the patient said: "I'm still regretting that I returned." She had no feelings of anxiety. Formerly she was a bit religious and afraid of death, now she is more religious and not afraid. We have no information about whether she had already been well informed of NDE before the event. One year after the event her experiences were published.

Case 5

Uzbek, female, Muslim, age at time of interview: 34 y. o.

The patient had a spine operation three years ago, but no reanimation. The patient remembers that she woke up with many male persons dressed in ancient Roman style and having had a feeling like going up to the mountains. We have no information whether she had already been well informed of NDE before the event.

Case 6

Uzbek, male, Muslim, age at time of interview: $47 \mathrm{y}$. o.

Six years ago the patient had a heart operation, after which he was in a coma for three days, but there was no reanimation. The patient does not remember anything, but he was well informed about NDE: He knows that people see or develop an extra sense, but he felt nothing. He wished he could remember something. But now he has a feeling that things which happen in his dreams finally come true.

Case 7

Uzbek, male, religion: no information, age at time of interview: $50 \mathrm{y}$. $\mathrm{o}$.

Five years ago the patient had a heart attack and was "clinically dead" for five minutes. No NDE was remembered. We do not know whether he had already been well informed of NDE before the event.

Case 8

(A report by a physician about an Uzbek male reanimated patient, no further data available)

The patient reported that everything was white. He saw a tree, street, grass. Everything was soft and smooth like walking on a bed sheet. We have no information whether he had already been well informed of NDE before the event. 
Case 9

Uzbek, male, religion: no information, older than 60 years.

Date of NDE not known. Patient had a stomach operation, and no reanimation was reported. He saw white dresses of doctors in a row but no persons in it. They were nine, but number four in the middle of them was dancing. He drew his vision like this:

Case 10

Uzbek, female, Muslim, age of time of interview: about $40 \mathrm{y}$. o.

One year ago she gave birth to a child, got a heavy fever afterwards and was four times reanimated. She remembered that somebody pulled her to a fire. After she recovered she asked herself: "Did I make so many sins? Had this been hell?" She reported these questions to her mother in law.

Case 11

Uzbek, male, atheist, age at time of interview: 58 y. o.

One month earlier he had a car crash, followed by reanimation. No NDE. He admitted that he already heard about NDE, but he never believed such things. He knows that nothing comes after death, and so it happened in his case, he argued.

Case 12

Uzbek, female, Muslim, and no further data - report by a physician

We do not know the antecedents but the patient was reanimated. She reported that she was flying over the earth. Everything was green and there were beautiful flowers; such beauty she had never seen in her life. She came to a beautiful house and met with her mother who had already been dead. Her mother told her: "You have to go back, you have children!" We have no information whether she had already been well informed of NDE before the event.

Case 13

Uzbek, female, Muslim, and no further data - report by a physician

We do not know the antecedents but the patient was reanimated. She reported that she was "up" and saw everything as down. She saw two lamps on the board and then her grandfather who was already dead. All was in white. We have no information whether she had already been well informed of NDE before the event.

\section{Results}

6 out of 13 patients were female (46\%). Data on age was available only for 9 of 13 patients: medium age was 41.1 years, median age: 40 years. The youngest patient was 23 years old, the oldest 58. NDE occurred 1 month to 7 years before the interviews. 
10 out of 13 patients were reanimated (76\%), and 3 were not $(23 \%)$. Of the 10 reanimated patients 6 reported about NDE phenomena $(60 \%)$. Of the 3 nonreanimated patients 2 reported about NDE.

9 patients were Muslims, 1 atheist, 3 unknown as to religion.

7 of the 9 Muslim patients had NDE (77.8\%), and 2 did not $(22.2 \%)$.

From 8 of 13 patients no data were available about whether they had already been well informed about NDE before the event. The other 5 admitted that they had been informed. The diagram below shows the distribution of experiences in the sample of the 13 patients.

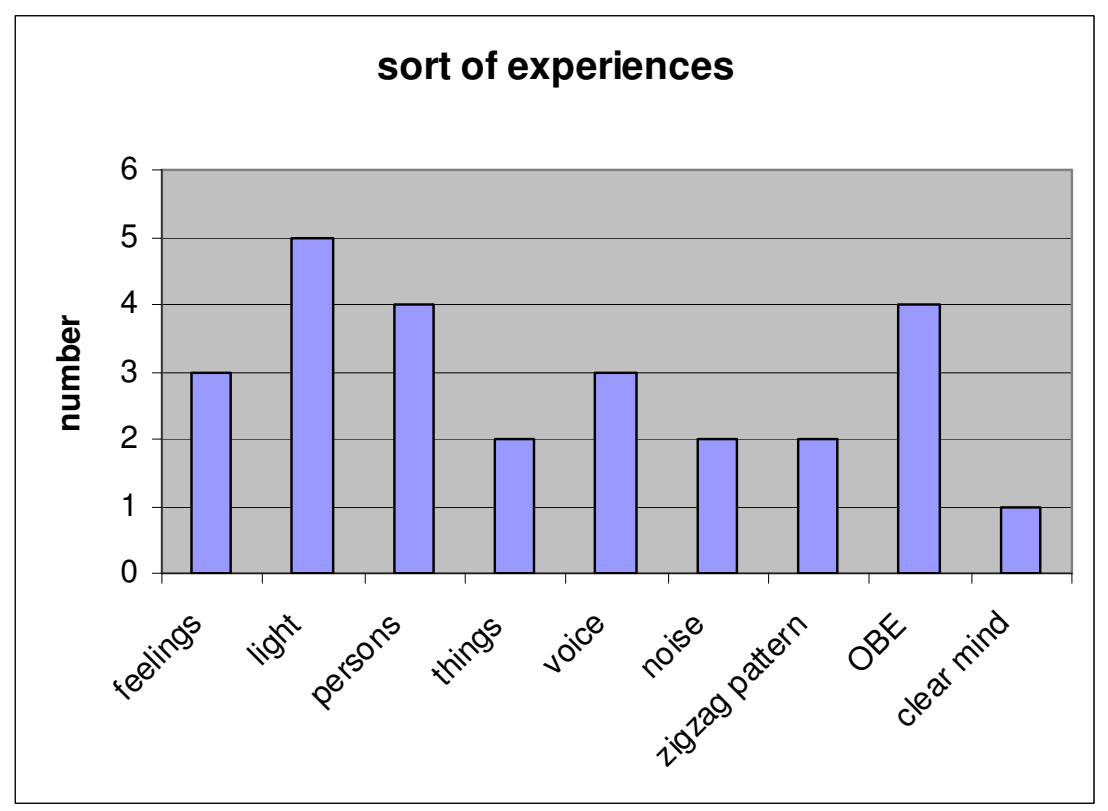

Explanation: "Feelings" include feelings of softness and smoothness or "tissuelike".

\section{Discussion}

The aim of finding an untouched population which had not heard about NDE was not fulfilled. In 1990, during the last month of Soviet Union, Raymond A. Moody's influential book Life after Life (1975) was first translated into Russian. The book (see photo) had also been available in the Uzbek Soviet Republic, where the Russian language was and is still well known by the Uzbek inhabitants. In the last two decades, many Russian TV documentaries were available on the topic of NDE, and these provided viewers with Western views of it. Therefore it is not surprising that the population in Central Asian countries had been well informed about NDE. 
Because of missing data and the small number of cases it cannot be proven whether patients who were informed before the event had a higher occurrence rate of NDE or not. On the other hand it is striking that none of the patients who were asked whether they already knew about NDE replied in the negative.

The most commonly reported phenomena were acoustic experiences ("voices" and "noise" together), light, feelings, and out-of body experiences (OBE's). The sample did not include tunnel phenomena, nor did film-clip-like experiences occur. In our pilot data, visions of light seem to play a prominent role. This phenomenon, plus the reported zigzag patterns, may provide a hint of a certain vulnerability of occipital lobe.

NDE in our report were heterogeneous and not stringently connected with clinical death or reanimation. This supports the criticisms that the notion of "NDE" is too broad because it does not require a connection with clinical death as "near death" implicates. Instead, our data supports the neuropsychological fact of multiple realizations of mental states, i.e., the same experiences or symptoms can be caused by completely different triggers. For instance, such triggers could be epilepsy, drug abuse, side effects of narcotic remedies and much more [4].

Most of the reports revealed descriptions which go along with personal experiences and remembrances, such as visions of dead family members, some in typical garment (blue chalat), or the door with typical Islamic ornamentation. In relation to this, it is worth discussing in case 4 if the ornaments of the door derive from a real remembrance of such a typical Uzbek wooden door or if the zigzag pattern (together with light!) which could be regarded as an occipital lobe malfunction was interpreted as ornaments. Indeed, traditional Islamic ornaments are often geometrical and could resemble a zigzag pattern.

In case 6 it is interesting that his attitude towards NDE was taken by the patient to lead him to divination, although he did not experienced NDE. In conclusion, not merely NDE alone but even the attitude towards NDE can alter religious or spiritual views or, reversely, there is some underlying tendency or need which leads to both the beliefs in NDE and in religion.

A limitation factor for those conclusions is the small sample size. The authors hope to provide the reader with more detailed data soon. 


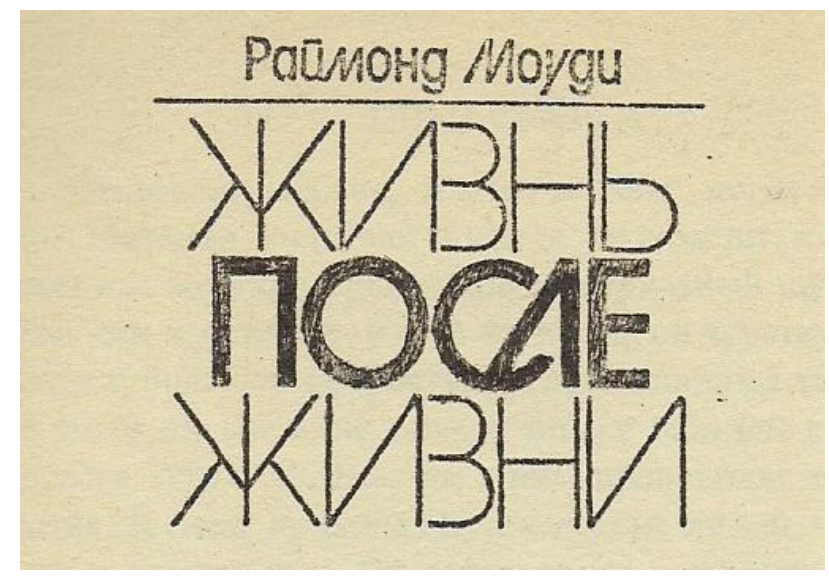

Cover picture of Russian 1990 edition of Raymond Moody's book Life after life.

In the literature, only a few reports or investigations about NDE in the Muslim world exist. Kreps [3] pointed out the strikingly low number of NDE reports in Islamic countries, unlike in the West. He concluded, that "NDEs are specifically designed for people who need them, and the need in certain communities may not be as great because of the persistence of traditional faith in an afterlife and a creator" (p67). Contrary to this position, Fracasso, Aleyasin and Young [2] reported about 19 Iran Muslims who had NDE. The authors saw many similarities in NDE to those of Westerners as for content and aftereffect. They also disagreed with the position that NDE are rare phenomena in Muslim world. On this view also Nahm and Nicolay [5] argue.

We think that both positions have problems. A systematic survey hasn't ever taken place to assess frequency of NDE in a population in Muslim countries, so all samples of investigated people are somewhat arbitrarily recruited. On the other hand, definition of term NDE is insufficient in that NDE reports are not only from people who had really been clinically dead but also (mostly) from people who had a great variety of triggers of "NDE" other than clinical death, such as "accidents" or "emotional shocks" (e. g. see Fracasso et al. [2]). In NDE field work, it is always a challenge to compare reports of patients (clients) with medical facts, e.g. a chart. But this hardly happens. This weakens conclusions about possible worldwide similarities. Nevertheless, attitudes towards NDE are a social phenomenon and thus influenced by a society's approach to NDE in relation to prevailing religious views. 


\section{Conclusions}

NDE are heterogeneous and not stringently connected with clinical death, and may also occur as connected to other events. Nor do NDE always occur in every case of clinical death. So the term NDE as it has been used until now as disconnected from clinical death is too broad, and leads to weak assertions. On the other hand, this situation demonstrates the neuropsychological phenomenon of multiple realizations of the same mental experiences caused by different triggers. In the sample, tunnel phenomenon and film clip like experiences were not reported. Acoustic phenomena, visions of light, feelings, and out-of-body experiences were most common. Experiences are influenced by cultural background and the patient's memories.

\section{Acknowledgement}

The authors thank Davlatyor Boltayev, Scientific Centre of Emergency Medicine, Urgench.

\section{References}

[1] B. Engmann, Nahtoderfahrungen - eine Gratwanderung zwischen Wissen und Glauben aus historischer Perspektive betrachtet. [NDE - a tightrope walk between knowledge and belief from a historical perspective], IZPP - International Journal for Philosophy and Psychosomatic Medicine, 1 (2012), www.izpp.de

[2] C. Fracasso, S.A. Aleyasin and M.S. Young, Brief Report: Near-Death Experiences among a Sample of Iranian Muslims, Journal of Near-Death Studies, 1 (2010), 265-272.

[3] J.I. Kreps, The search for Muslim near-death experiences, Journal of NearDeath Studies, 2 (2009), 67-86.

[4] D. Mobbs and C. Watt, There is nothing paranormal about near-death experiences: how neuroscience can explain seeing bright lights, meeting the dead, or being convinced you are one of them, Trends in Cognitive Sciences, 10 (2011), 447-449.

[5] M. Nahm and J. Nicolay, Essential features of eight published Muslim neardeath experiences: an addendum to Joel Ibrahim Kreps's "The search for Muslim near-death experiences", Journal of Near-Death Studies, 1 (2010), 255-263. 
[6] I. Schmied-Knittel, Nahtoderfahrungen. [near-death experiences], http://www.igpp.de/german/eks/schmied_nahtoderfahrung.pdf

Received: October, 2012 